\title{
Rheological and Physical Properties of Ionic Liquids with Ammonium Cations as Synthetic Lubricants
}

\author{
R.A.El-Nagar ${ }^{* 1}$, S.K.Attia ${ }^{1}$, S.A.Rizk ${ }^{2}$, D.I. Osman ${ }^{1}$, R.I.Abdallah ${ }^{1}$ \\ ${ }^{1}$ Egyptian Petroleum Research Institute. P.O. Box 11727, Nasr City, Cairo, Egypt. \\ ${ }^{2}$ Chemistry Department, Faculty of Science, Ain Shams University, Cairo, Egypt.
}

\begin{abstract}
ONIC liquids possess different properties which make them a high potential as lubricants. In our work series of five ammonium salts ionic liquids were synthesized by using different C-chain carboxylic acids with ethanol amines and evaluated. The physicochemical properties and rheological behavior investigated for their potential use as synthetic lubricants. The prepared Ils show high thermal stability, good fluidity characters and the viscosity increases with increasing C-number (become thicker) which converted from liquid phase to semisolid phase (grease). Ia-Ic shows Newtonian behavior for and pseudoplastic behavior for Id and Ie.
\end{abstract}

Keywords: Ionic liquid, Fatty acid, Physicochemical properties, Rheological behavior, Synthetic lubricants.

\section{Introduction}

Lubrication technology is always facing new difficulties so; it must be developed and advanced. All industrial fields aim to increase durability and service intervals and reduce friction which results in energy usage $[1,2]$. To overcome these difficulties and challenges new lubricants [3] and more specified additives must be used.

Lubricant's main usage is to control wear and friction and reduce the contact temperature. Formulation of lubricants is depending on the base oil either synthetic or mineral or grease with different additives [4].

Ionic liquids (ILs) are considered as one of the key of solution in the coming generation of lubricants. In 2001 was the first discovery of ILs as highly specified synthetic lubricants, and was the first testing it for tribology techniques $[5,6]$ and after that open new research fields such as corrosion protection, antioxidant and pour point depressant [7-9].

All these applications are due to its characterization [10], which can be briefed in low volatility, inflammability, thermal stability, miscibility with organic solvents and chemical composition which consists of organic cation and inorganic anions $[11,12]$. Most of published papers in ILs as lubricants have been interested with engine lubricating and micro-electrochemical machines (MEMS) [13, 14]

Rheological properties of materials play important role in describing heat transfer. For oil, rheological properties depend on several factors such as temperature, concentrations, shear rate, pressure, time, and chemical properties. The most important that the researches focused on it was the effect of temperature on fluid viscosity [15].

In our work we are interested to synthesize series of hydroxyl ammonium ionic liquids by using different $\mathrm{C}$-chain of carboxylic acids with ethanol amine. The prepared ionic liquids elevated, characterized and the rheological behavior and fluidity investigated for their potential use as synthetic lubricants.

\section{Experimental}

Materials and Method

Diethanol amine (99\%), acetic acid (99\%), butyric acid (99\%), hexanoic acid (98\%), octanoic

Corresponding author e-mail: raghda_elnagar@yahoo.com,

Tel: +201224154876, Fax: + (202)22747433.

DOI: 10.21608/EJCHEM.2018.2287.1189

C2017 National Information and Documentation Center (NIDOC) 
acid (98\%), oleic acid (98\%), acetone (99\%). were purchased from Sigma-Aldrich chemical Co. and Merck.

Neutralization reaction of amines with different acids is the most common technique for the synthesis of hydroxyl ammonium salts ionic liquids [16]. (Scheme 1) Diethanol amine (0.5 Mole) placed into $300 \mathrm{~mL}$ flask in water bath, the system was supplied with a condenser and stirring at constant rate. Acids (acetic acid, butyric acid, hexanoic acid, octanoic acid and oleic acid $(0.5$ mole $))$ were added drop wise to the stirred diethanol amine in about $15 \mathrm{~min}$ and the reaction continued to about $30 \mathrm{~min}$. The yield treated with acetone and get rid of it by evaporation under vacuum, dry the treated yield for $48 \mathrm{~h}$ at $323 \mathrm{k}$.

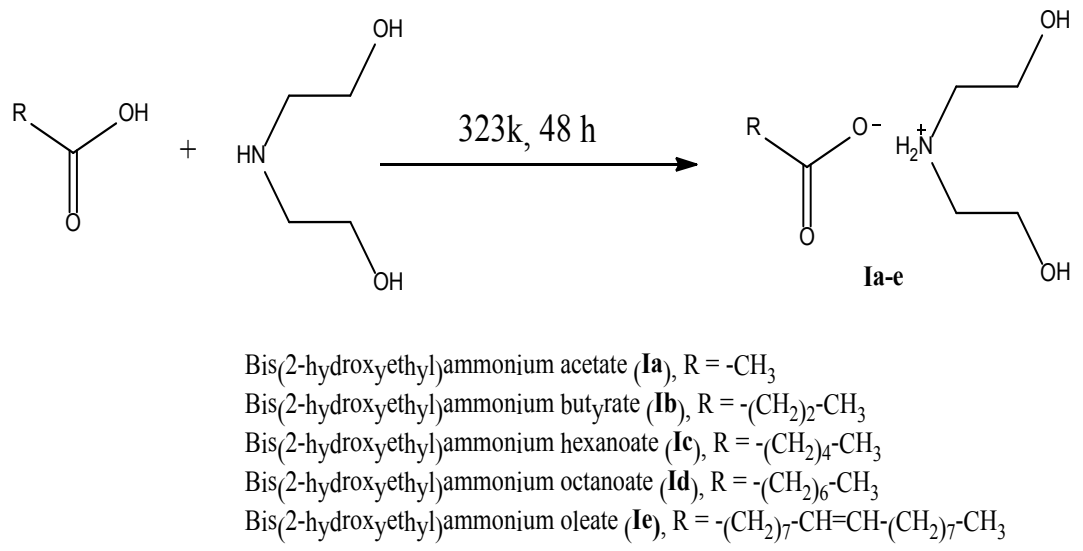

Scheme 1. Neutralization reaction of amines with different acids [16-18].

\section{Characterization}

The prepared hydroxyl ammonium ionic liquids are elevated via the traditional tools of analysis, Infra-Red (Spectrum-One Perkin- Elmer) spectroscopy, Thermal Gravimetric Analysis (TGA) and Elemental analysis (Elemental analyzer PerkinElmer $24^{\circ} \mathrm{C}$ ).

\section{Physical properties}

Their physical properties were determined according to standard test methods fluid test and rheological behaviors were studied.

\section{Test fluid}

Four synthesized hydroxyl ammonium ionic liquid were investigated, and two reference lubricants were chosen with different composition reference oil 1 and 2 . Ref 1 was synthetic oil (hydrocarbon and ester) and corrosion inhibitor was added, also Ref 2 was mineral oil based lubricants and antioxidant and corrosion inhibitor were added.

\section{Test Fluid Method}

This test was performed in two steps [19], starting with heating of known quantities of the synthesized ionic liquids up to $100^{\circ} \mathrm{C}$ for six days. To accelerate thermal oxidation, copper strips were added, the yield was tested for viscosity, copper content and mass change.
In the second step, the oxidative aging was completed with the obtained samples from the first step for another six days but raise temperature to $150^{\circ} \mathrm{C}$, the yield samples were analyzed as in the first step.

Densities were elevated using denstimeter, Kinematic viscosity using viscometer, and mass changing using an analytical balance.

\section{Result and Discussion}

Characterization of the prepared hydroxyl ammonium ionic liquids

The spectra of the studied samples were measured in the range of 400-4000 $\mathrm{Cm}^{-1}$ with suitable scan resolution $4 \mathrm{Cm}$ and scan rate $32 \mathrm{Cm} /$ min. The formation of hydroxyl ammonium salts was confirmed using FTIR as illustrated in Fig. 1-5 and Table 1. The broad band of stretching (NH) group was noticed at 3327, 3309, 3304, 3303 and $3319 \mathrm{Cm}^{-1}$ for Ia, Ib, Ic, Id and Ie respectively. The spectra of carbonyl group which appear as sharp peak was noticed at 1566, 1457, 1454, 1454 and $1560 \mathrm{Cm}^{-1}$ and stretching $\mathrm{CH}_{2} \& \mathrm{CH}_{3}$ vibration was at 2851,2926, 2962, 2865 and $2854 \mathrm{Cm}^{-1}$ for $\mathrm{Ia}, \mathrm{Ib}, \mathrm{Ic}$, Id and Ie in order. Finally $\mathrm{C}-\mathrm{C}$ bond was confirmed by the spectra which appear at 1071 $\mathrm{Cm}^{-1}$ for all the prepared compounds.

H-NMR spectra for the prepared materials 


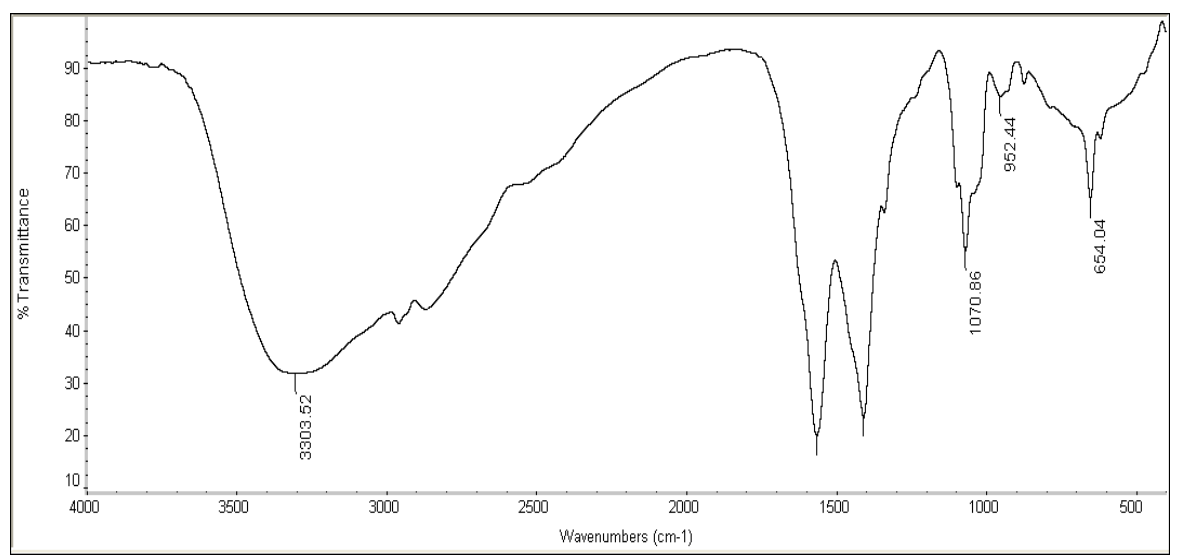

Fig. 1. FT-IR spectra of Ia.

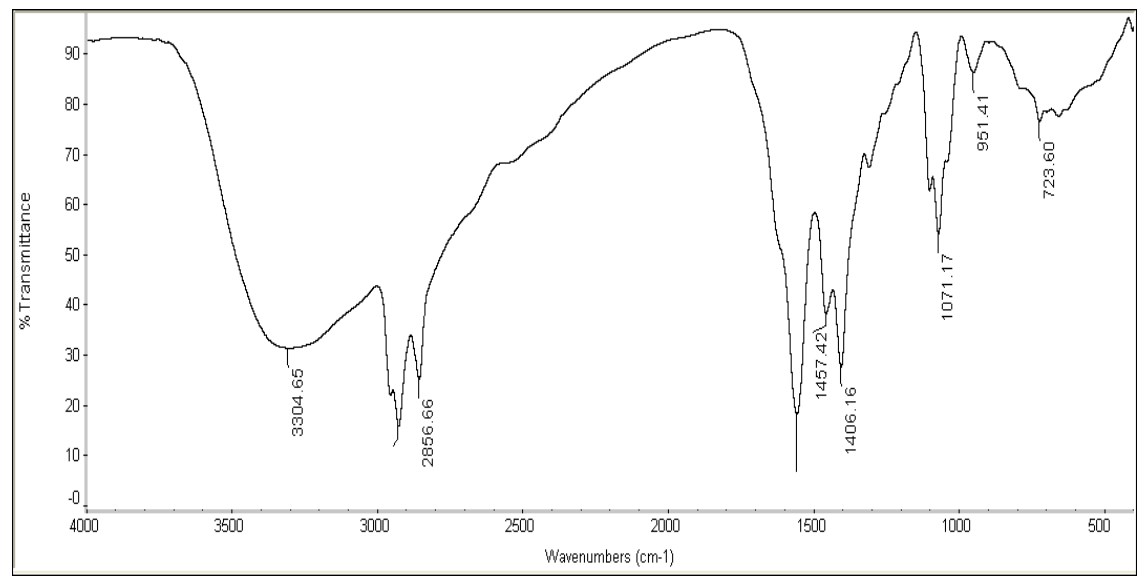

Fig. 2. FT-IR spectra of Ib.

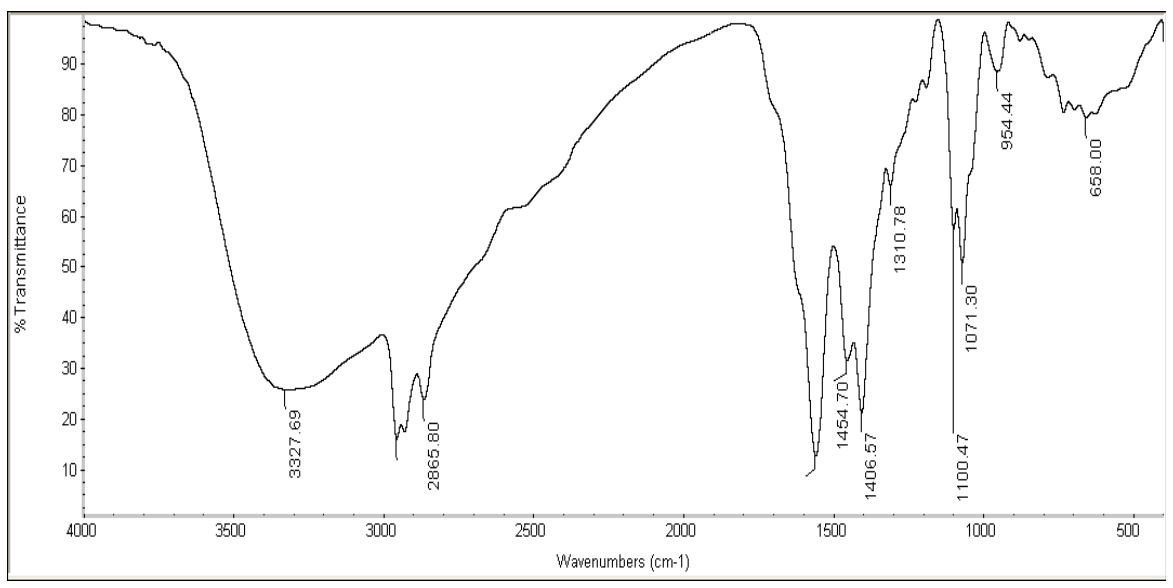

Fig. 3. FT-IR spectra of Ic. 


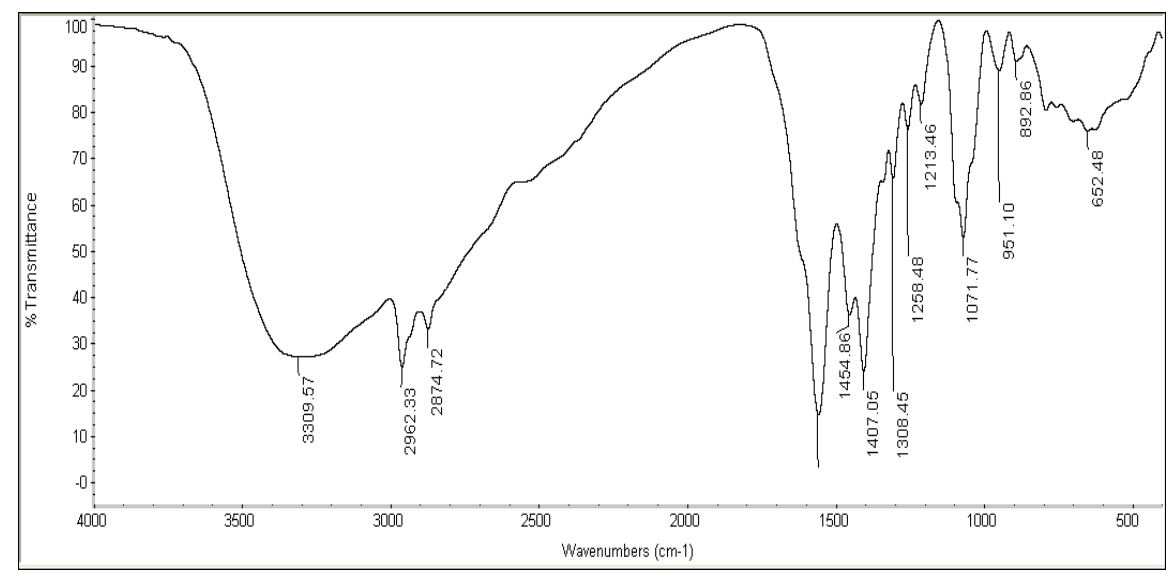

Fig. 4. FT-IR spectra of Id.

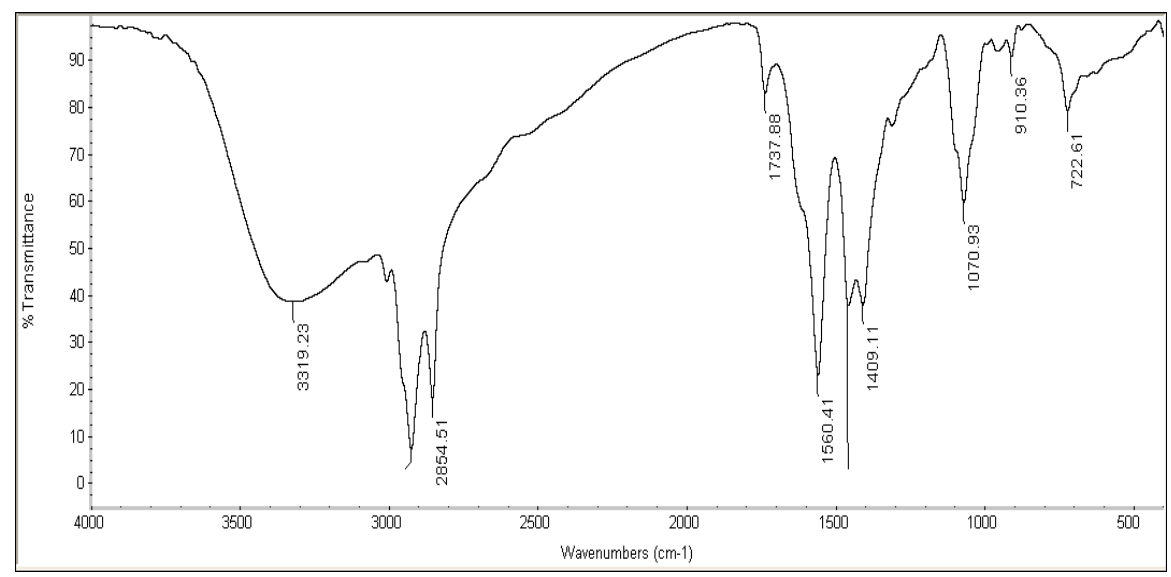

Fig. 5. FT-IR spectra of Ie.

TABLE 1. IR spectroscopy for prepared hydroxyl ammonium salts.

\begin{tabular}{ccccc}
\hline Cpd. & $\mathbf{N}-\mathbf{H}$ & $\mathbf{C H}_{2} \& \mathbf{C H}_{3}$ & $\mathbf{C}-\mathbf{C}$ \\
\hline Ia & 3327 & 2851 & 1566 & 1071 \\
Ib & 3309 & 2926 & 1457 & 1071 \\
Ic & 3304 & 2962 & 1454 & 1071 \\
Id & 3303 & 2865 & 1454 & 1071 \\
Ie & 3319 & 2854 & 1560 & 1071 \\
\hline
\end{tabular}

were obtained using Jeol-EX $270 \mathrm{MHz} \mathrm{H}^{1}$-NMR spectroscopy. The spectrometer operating at 400.13 MHzand used 5-mm broad band inverse Z-gradient probe in DMSO- $\mathrm{d}_{6}$ solvent.

The data from Table 2 reveals that:

Proton (a) has high $\delta$ value which was attributed to highly deshielded proton because of the positively charged nitrogen atom. $\delta$ value of proton (c) is higher than that of proton (b) due to the highly electro negativity of oxygen atom more than nitrogen atom and the shielded proton (d) has law $\delta$ value. The singlet shielded proton (e) differ in $\delta$ values which record $2.2,0.90,0.90,0.88$ and $0.88 \mathrm{ppm}$ for Ia, Ib, Ic,Id and Ie respectively and that were illustrated by the nearest of oxygen

Egypt.J.Chem. 61, No.2 (2018) 
atom. Protons (h), (f), (g) and (i) are shielded protons with law $\delta$ values, $\delta$ value of proton (h) is higher than those of (f) and ( $\mathrm{g}$ ) due to the nearest of oxygen atom and become far away from $\mathrm{CH}_{3}$ which act as electron donating. For proton (k), it has $\delta$ value of $5.48 \mathrm{ppm}$ and that illustrated by neighboring of $\mathrm{C}=\mathrm{C}$.

TABLE 2. H $^{1}$-NMR spectroscopy of (Ia, Ib,Ic,Id and Ie).

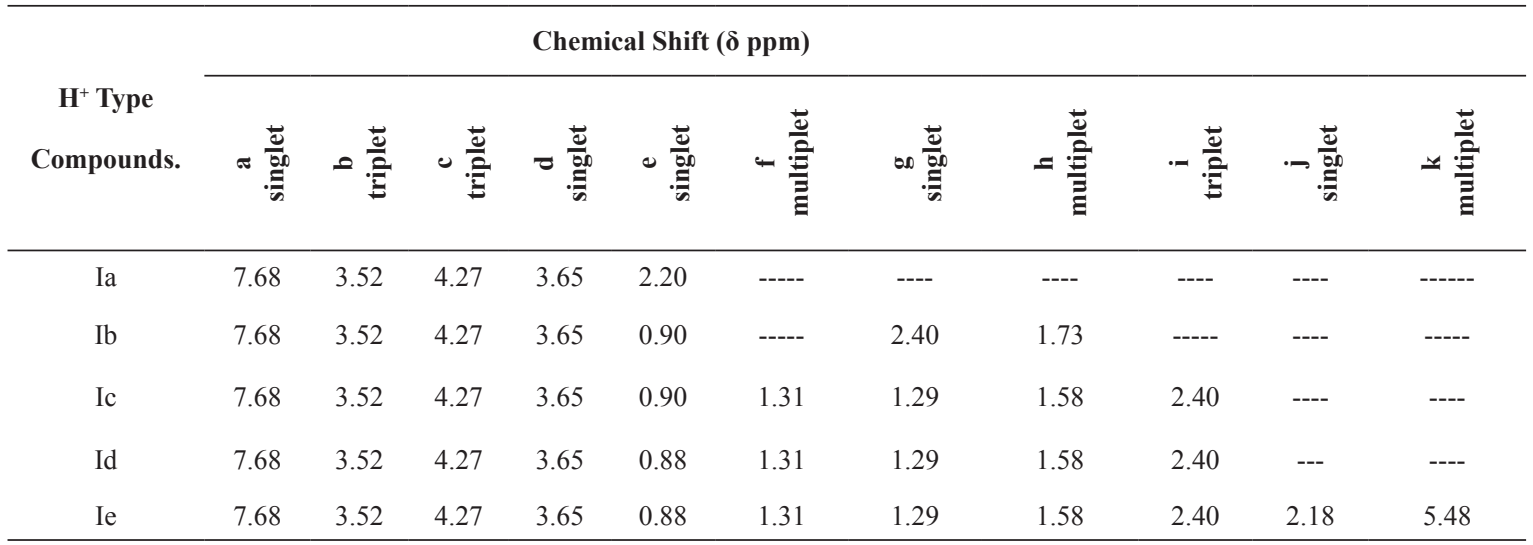<smiles>CC(=O)[O-]</smiles>

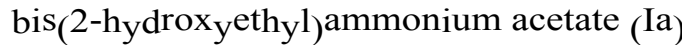<smiles>CCCC(=O)[O-]</smiles>

bis $\left(2-h_{y} d r o x_{y}\right.$ ethyl) ammonium but yrate $_{\text {(Ib) }}$<smiles>CCCCCC(=O)[O-]</smiles>

bis 2 -hydroxy ethyl $_{\text {ammonium hexanoate(Ic) }}$<smiles>CCCCCCCC(=O)O</smiles>

bis(2-hydrox $x$ ethyl $)$ ammonium octanoate (Id

bis (2-hydrox ethyl $_{\text {ammonium }}(E)$-octadec-9-enoate<smiles></smiles>

bis $\left(2-h_{y} d_{\text {rox }}\right.$ ethyl $)$ ammonium $(E)$-octadec-9-enoate (Ie)

Fig. 6. H1-NMR spectroscopy of (Ia, Ib,Ic,Id and Ie). 
Elemental analysis

The data obtained from Table 3 show that the calculated values of the elements were in good compatibility with the found values.

TABLE 3. Elemental analysis for the prepared hydroxyl ammonium salts.

\begin{tabular}{|c|c|c|c|c|c|c|}
\hline \multirow[b]{2}{*}{ ILs } & \multicolumn{2}{|c|}{$\% \mathrm{C}$} & \multicolumn{2}{|c|}{$\% \mathrm{~N}$} & \multicolumn{2}{|c|}{$\% \mathrm{H}$} \\
\hline & Calc. & Found & Calc. & Found & Calc. & Found \\
\hline $\mathrm{Ia}$ & 43.63 & 43.42 & 8.48 & 8.19 & 9.15 & 9.65 \\
\hline $\mathrm{Ib}$ & 49.72 & 49.64 & 7.25 & 7.60 & 9.91 & 9.64 \\
\hline Ic & 54.28 & 54.44 & 6.33 & 6.27 & 10.48 & 10.38 \\
\hline Id & 57.80 & 57.57 & 5.62 & 5.98 & 10.91 & 10.78 \\
\hline $\mathrm{Ie}$ & 68.17 & 67.27 & 3.61 & 3.91 & 11.6 & 12.2 \\
\hline
\end{tabular}

The synthetic ionic liquids have regioselective isomerization of the amide to amido-enaminol tautomeric group that was clear in IR and ${ }^{1} \mathrm{H}-\mathrm{NMR}$, in situ that able to extract most of the corrosive materials and free radical tumor as outlined in Fig.7. So, they can be considered as anticorrosion, antioxidant lubricating oil. These powerful materials have considered becoming a new approach to green chemistry (simplicity, mild conditions, and atomic economy), Green chemistry approach toward the synthesis of ionic liquids with novel characteristics through amideenaminol group has several. In this study, authors believe the synthesized ionic liquids may provide a "green" alternative four derivatives to develop lubricating with novel characteristics.<smiles>[R]C=CC[N+](CCO)=C(CCO)CCCCC</smiles>
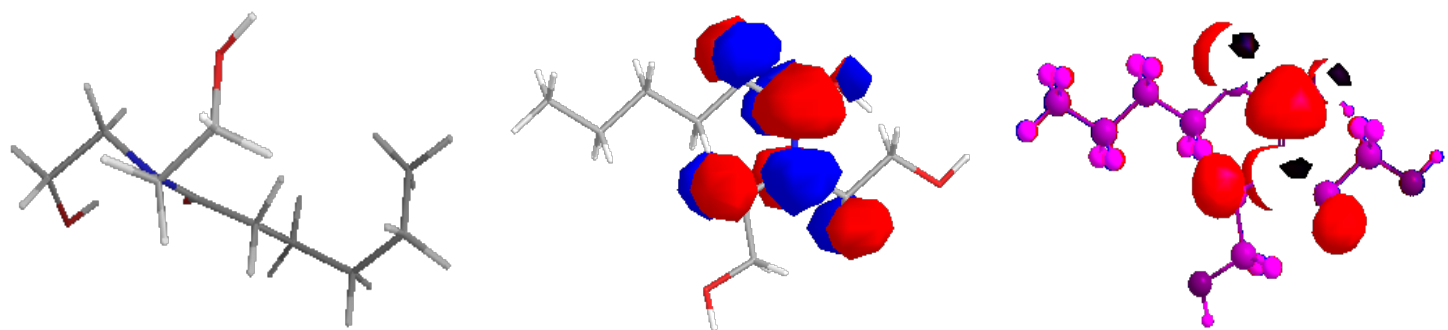

Fig. 7. outline the electronic distribution of the amide-enaminol isomers that responsible for scavenging the free radical and corrosive materials

Thermal stability was measured by thermogravimetric analysis. The data were obtained by SDT Q600 V20.5 Build 15 thermal analyzer. Samples are heated from ambient temperature to $600^{\circ} \mathrm{C}$ at heating rate of $10^{\circ} \mathrm{C} \mathrm{min}-1$ and nitrogen flow. From Fig. 8, we found that, the all prepared ILs show good thermal stability and the final degradation temperature increased with increasing the carbon number of acid part.

Egypt.J.Chem. 61, No.2 (2018) 


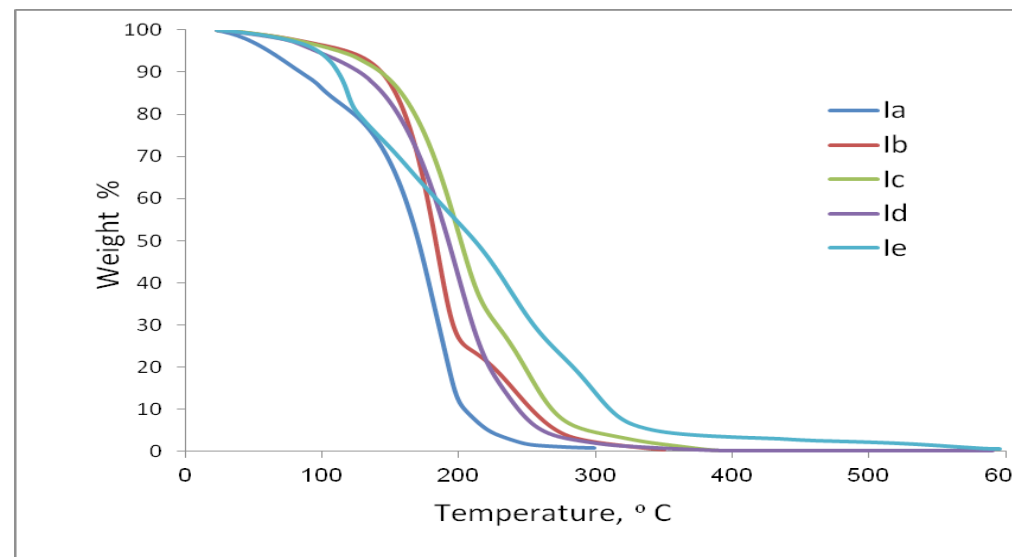

Fig. 8. Thermal gravimetric analysis for the prepared ILs (Ia-Ie).

Physical properties of the prepared hydroxyl ammonium ionic liquids

Viscosity is one of the most effective properties of lubricants because it is the first operating characteristics determined to any lubricating oil. Mainly viscosity measures the flow resistance and a good lubricant has enough fluidity to reduce friction at low temperatures.

From data obtained in Fig. 9 we found that the viscosity decreases with increasing temperature so the lubricants become thinner as increasing the operating temperature. A good lubricating must have stable viscosity and the rate of changing of viscosity with temperature is measured via arbitrary scale known as viscosity index. If the viscosity falls rapidly due to temperature increasing, it has low viscosity index on the other hand if the viscosity is only slightly affected by temperature raising the viscosity index will be high.

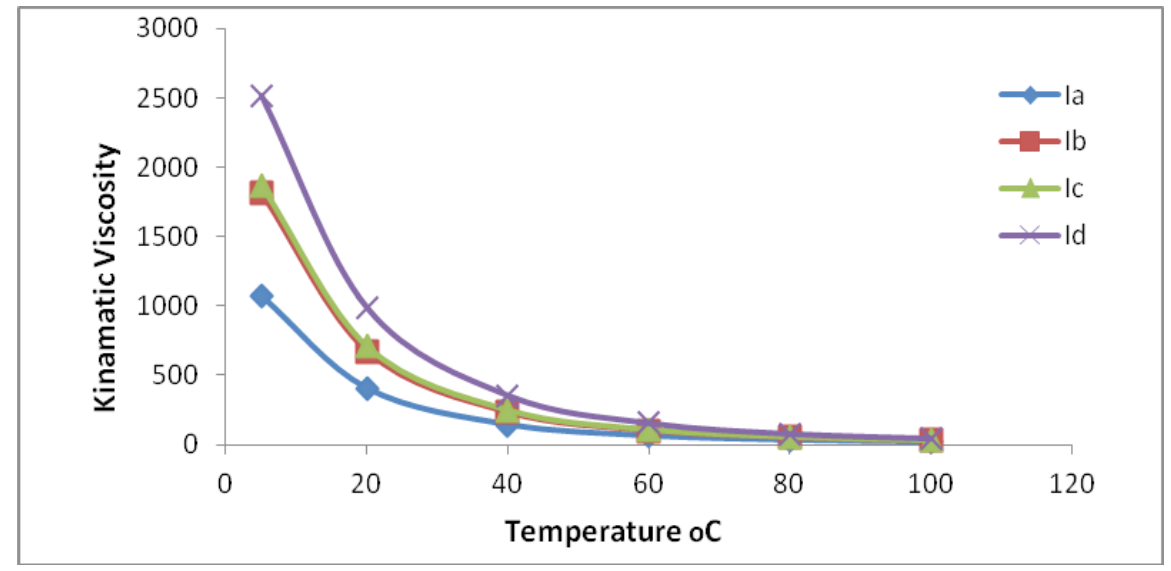

Fig. 9. Relation between kinematic viscosity and temperature.

Also, the viscosity increase with increasing C-number of acid parts from Ia-Id the lubricants become thicker and converted from liquid phase to semisolid (grease) phase Ie as shown in Table 4.

Cloud and pour points indicate the suitability of lubricants in cold conditions. Lubricants used in machines working at low temperatures should possess low pour point; otherwise solidification of lubricant oil will cause jamming of machine.

Flash point is important factor in determining how oil well behaves and we found that all prepared Ils process slightly high flash point which is accepted value as potential lubricants.

TAN is indication of the formation quality. In Table 4, we found that all prepared Ils have no acidic number. 
TABLE 4. Physical properties of ILs (Ia-Id).

\begin{tabular}{llcccc}
\hline \multicolumn{1}{c}{ Test } & \multicolumn{1}{c}{ Method } & Ia & Ib & Ic & Id \\
\hline Pour point, ${ }^{\circ} \mathrm{C}$ & ASTMD-97 & $<-45$ & $<-45$ & $<-45$ & $<-45$ \\
Flash point, ${ }^{\circ} \mathrm{C}$ & ASTMD-92 & 184 & 190 & 193 & 198 \\
Fire point, ${ }^{\circ} \mathrm{C}$ & 201 & 205 & 211 & 218 \\
Density & ASTMD-4052 & 1.1800 & 1.1091 & 1.0624 & 1.0335 \\
Viscosity@40 $40^{\circ} \mathrm{C}, \mathrm{St}$ & & 143.2 & 231.39 & 248.15 & 355.28 \\
Viscosity @ $100^{\circ} \mathrm{C}, \mathrm{St}$ & ASTMD-445 & 19.58 & 29.01 & 31.72 & 45.93 \\
Viscosity Index & & 159.57 & 164.55 & 170.82 & 189.12 \\
TAN & & Nil & Nil & Nil & Nil \\
\hline
\end{tabular}

TABLE 5. Physical properties of IL (Ie).

\begin{tabular}{lcc}
\hline \multicolumn{1}{c}{ Test } & Method & Ie \\
\hline Oil Separation & & Zero \\
Flash point, ${ }^{\circ} \mathrm{C}$ & & 202 \\
Fire point, ${ }^{\circ} \mathrm{C}$ & ASTMD-92 & 235 \\
Density@15.56 & ASTMD-4052 & 1.0109 \\
Viscosity @ $120^{\circ} \mathrm{C}, \mathrm{St}$ & ASTMD-445 & 18.004 \\
TAN & ASTMD-664 & Nil \\
\hline
\end{tabular}

\section{Fluids test}

Aging behavior of the four synthesized ionic liquids at $100^{\circ} \mathrm{C}$ are different from their behavior at $150^{\circ} \mathrm{C}$ as shown in Table 6. Mass change of ILa and ILbare around $0.1(\mathrm{wt} \%$ ) and negligible for ILc and ILd at $100^{\circ} \mathrm{C}$. At $150^{\circ} \mathrm{C}$, negligible mass change for all synthesized ionic liquids are found and also for the reference oils.
Changing in viscosity of the synthesized ionic liquids at $40^{\circ} \mathrm{C}$ is due to long-term exposure at different temperature. As the viscosity increase the low thermal stability obtained, so ILa-ILd show high thermal stability and good fluidity characters.

TABLE 6. Aging behavior of ILa-ILd and reference oils ( $\operatorname{Ref} 1 \& 2$ ).

\begin{tabular}{ccccc}
\hline \multirow{2}{*}{ Sample fluid } & \multicolumn{2}{c}{$\mathbf{1 0 0}^{\circ} \mathbf{C}$ for $\mathbf{6}$ days } & \multicolumn{2}{c}{$\mathbf{1 5 0}^{\circ} \mathbf{C}$ for further $\mathbf{6}$ days } \\
\cline { 2 - 5 } & $\begin{array}{c}\text { Mass Change } \\
(\mathbf{W t} \mathbf{~ \% )}\end{array}$ & $\begin{array}{c}\text { Viscosity Change } \\
\mathbf{( \% )}\end{array}$ & $\begin{array}{c}\text { Mass Change } \\
\mathbf{( W t ~ \% )}\end{array}$ & $\begin{array}{c}\text { Viscosity Change } \\
(\mathbf{\%})\end{array}$ \\
\hline ILa & -0.15 & -9 & Negligible & -7 \\
ILb & -0.10 & -5 & Negligible & -3 \\
ILc & Negligible & -1 & Negligible & -1 \\
ILd & Negligible & Negligible & Negligible & -1 \\
Ref 1 & Negligible & Negligible & Negligible & 2 \\
Ref 2 & Negligible & Negligible & Negligible & 6 \\
\hline
\end{tabular}

\section{Rheological behavior}

The rheological behaviors of the five prepared hydroxyl ammonium ionic liquids (Ia-Ie) were tested at temperatures $5,20,40,60,80$, and $100^{\circ} \mathrm{C}$ (Fig.10-15), the relations between viscosity vs. shear rate at highest temperature and the lower observed as shown in Fig. 11,13, the relations between shear stress vs. shear rate at highest temperature and the lower observed as shown in Fig. 12,14 and Viscosity vs. different c-chain of acids were evaluated and shown in Fig. 15. 
From date we found that the prepared ionic liquids showed non-Newtonian behavior at low and high temperatures, also showed increase in viscosity at low shear rate and vice versa. the high dynamic viscosity at low shear rate means higher torque is required to start the rotating motion. This behavior no time dependence and the shear applied break down the internal structure within the fluid very rapidly therefore reduces the mechanical efficiency of the hydraulic system.

From Fig. 15, we notice that the viscosities of the prepared ionic liquids increased with increasing C-number of acid part and the prepared samples converted from liquid phase in Ia, Ib, Ic and Id to semisolid grease in Ie ionic liquids.

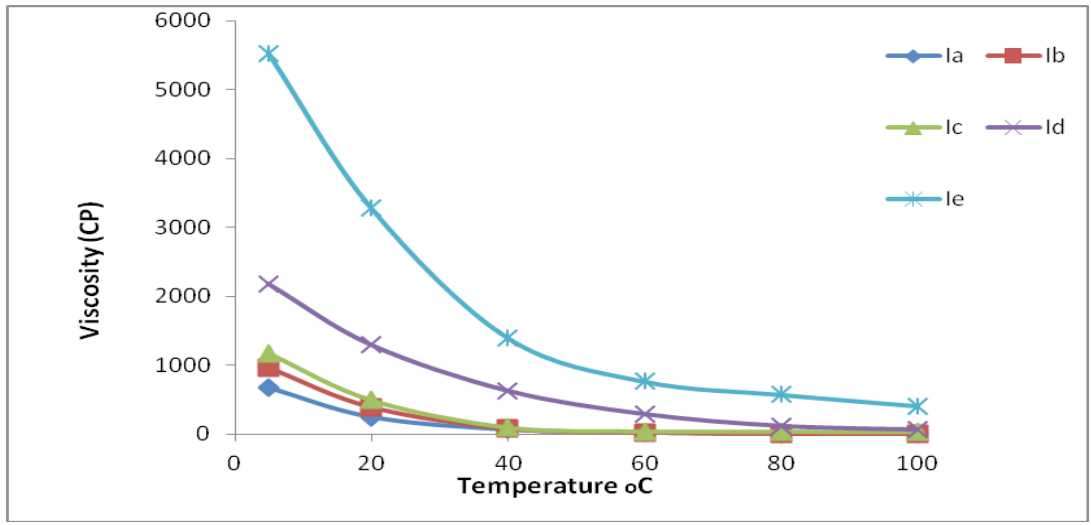

Fig. 10. Relation between viscosity (CP) and temperature (oC) for ILs (Ia-Ie).

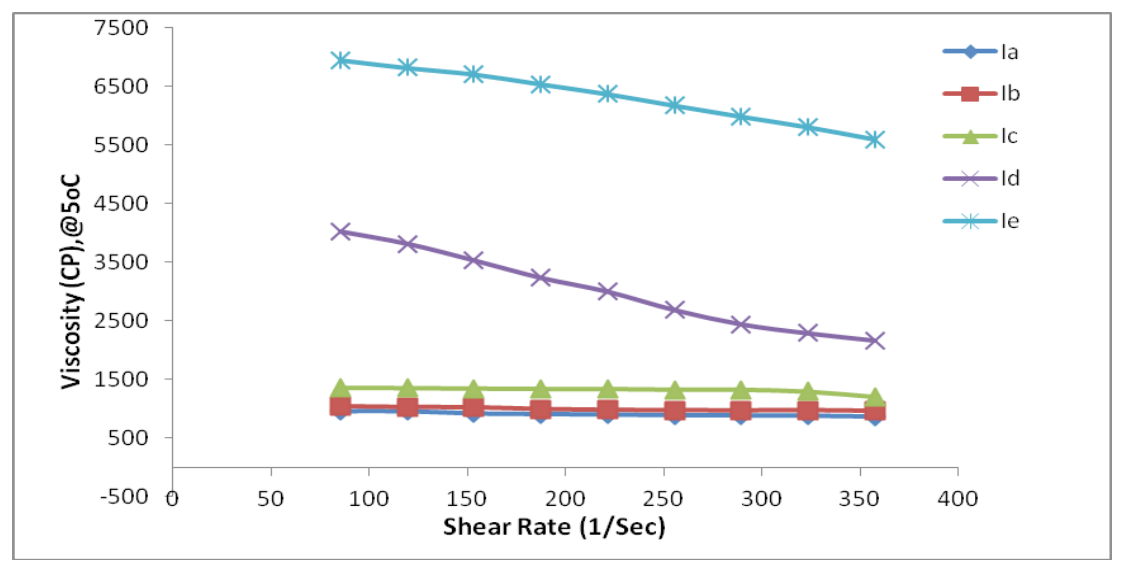

Fig. 11. Relation between viscosity (CP) and shear rate at low temperature for ILs (Ia-Ie).

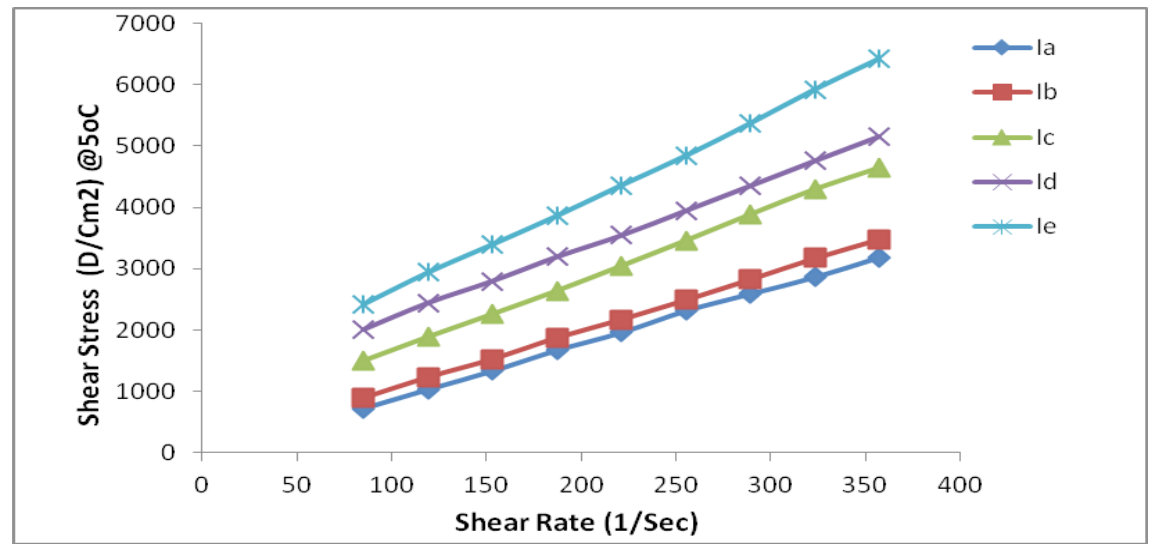

Fig.12. Relation between shear stress and shear rate at low temperature for ILs (Ia-Ie). 


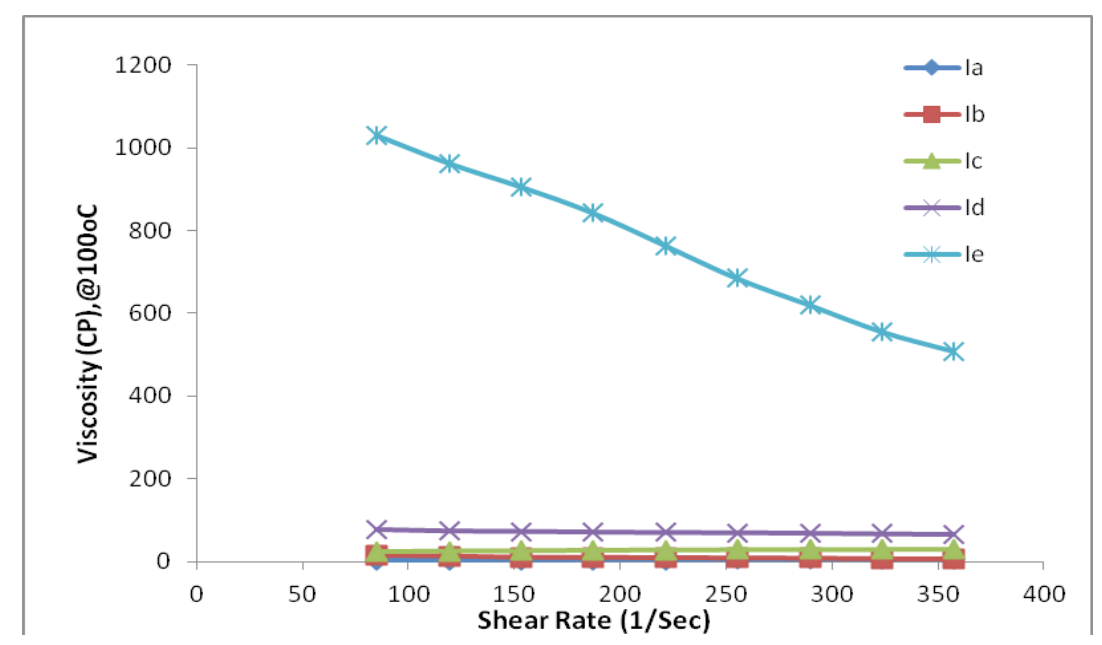

Fig. 13. Relation between viscosity (CP) and shear rate at high temperature for ILs (Ia-Ie).

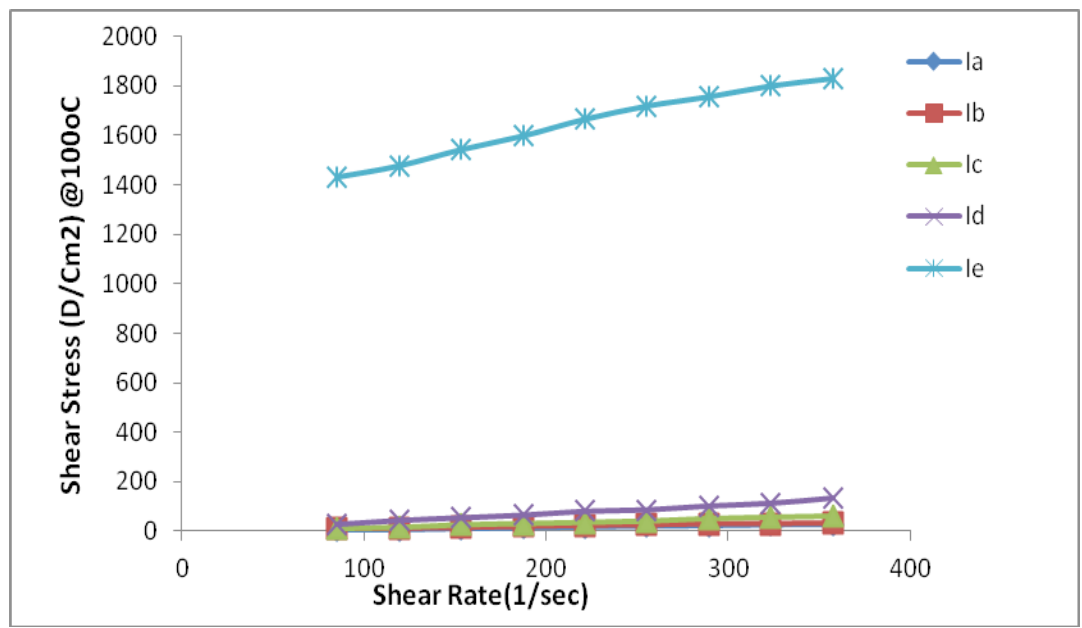

Fig. 14. Relation between shear stress and shear rate at low temperature for ILs (Ia-Ie).

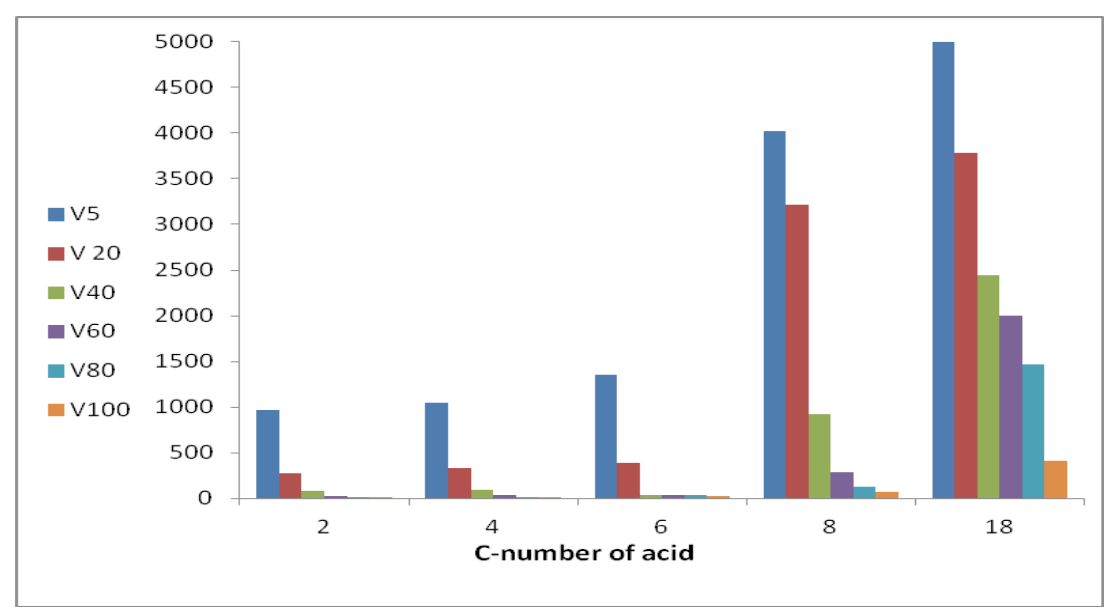

Fig. 15. Relation between viscosity (CP) and C-number of acid at temperature for ILs (Ia-Ie). 


\section{Conclusion}

Series of five ammonium salts ionic liquids were prepared and studies from physicochemical, rheological and fluidity point of view and the conclusion can be noted in:

- All prepared Ils have physicochemical properties which accepted to behave as potential lubricants and having no acidity characters indicate high quality formulation.

- The prepared Ils show high thermal stability and good fluidity characters.

- The viscosity increase with increasing $\mathrm{C}$-number of acid parts (become thicker) and converted from liquid phase to semisolid phase (grease).

- Rheological study showed Newtonian behavior for Ia-Ic and pseudoplastic behavior for Id and Ie.

\section{References}

1) Street K.W., Morales W., Koch V.R., Valco D.J., Richard R.M., Hanks N., Evaluation of vapor pressure and ultra-high vacuum tribological properties of ionic liquids, Tribol. Trans. 54, 911919 (2011).

2) Palacio M., Bhushan B., A Review of Ionic Liquids for Green Molecular Lubrication in Nanotechnology, Tribology Letters. 40, 247-268 (2010).

3) Heikal E. K., Elmelawy M.S., Khalil S. A., Elbasuny N.M., Catalytic behavior of Pt nanoparticles dealuminated Y-zeolite for some n-alkane hydroisomerization. Egyptian Journal of Petroleum. 26, 53-59 (2017).

4) Stachowiak G.W, Batchelor A.W. , Engineering Tribology, The interdisciplinary nature of tribology encompasses knowledge drawn from disciplines such as mechanical engineering, Materials Science, Chemistry and Physics, $\mathbf{5}$, 1247-1275 (2005).

5) Ye C.F., Liu W.M., Chen Y.X., Yu L.G., Roomtemperature ionic liquids: a novel versatile lubricant, Chemical Communications. 21, 22442245 (2001).

6) Minami I., Ionic liquids in tribology. Molecules, 14, 2286-305 (2009).

7) Zhou F., Liang Y., Liu W., Bioinspired catecholic chemistry for surface modification. Chemical Society Review. 38, 2590-2599 (2009).
8) Uerdingen M., Treber C., Balser M., Schmittc G., Werner C., Corrosion behavior of ionic liquids. Green Chemistry 7, 321-325 (2005).

9) Cao Y., Chen Y., Sun X., Zhang Z., Mu T., Water sorption in ionic liquids: kinet- ics, mechanisms and hydrophilicity Physical Chemistry Chemical Physics. 14, 12252-12262 (2012).

10) El-Nagar R.A., Nessim M., Abd El-Wahab A., Ibrahim R., Faramawy S., Investigating the efficiency of newly prepared imidazolium ionic liquids for carbon dioxide removal from natural gas Journal of Molecular Liquids. 237, 484-489 (2017).

11) Pham T.P.T., Cho C.W., Yun Y.S.., Environmental fate and toxicity of ionic liquids. Water Research. 44, 352-372 (2010).

12) Stachowiak G.W, Batchelor A.W., Engineering Tribology, 5, 1247-1275 (2005).

13) Pu J., Wang L., Mo Y. , Xue Q., Journal of. Colloid and Interface Science 354, 858-865 (2011).

14) Zhao W., Wang Y., Wang L., Bai M., Xue Q., Physicochemical and Engeneering Aspects, 361, 118-125 (2010).

15) Nessim M.I., Abdallah R.I., Elsayed G.E., ElNagar R.A., Effect of Ionic Liquids in $\mathrm{CO} 2$ Capture from Natural Gas, Life Science Journal, 10, 1716-1723 (2013).

16) Zhai L., Zhong Q., He C., Wang J., Hydroxyl Am-monium Ionic Liquids Synthesized by WaterBath Mi-crowave: Synthesis and Desulfurization. Journal of Hazardous Materials, 177, 807-813 (2010).

17) Santos D., Lourenc E., Santos M. F.C., Franceschi E., Dariva C., Barison A., Zuber A., Castier M., Mattedi S., Volumetric properties of binary aqueous solutions of protic ionic liquids based on bis (2-hydroxyethyl) ammonium. Journal of Molecular Liquids, 7 , 48 (2016).

18) Malyanah Mohd Taib, Majid Majeed Akbar, Thanapalan Murugesan, "Densities, refractive index and excess properties of bis(2 hydroxyethyl) ammonium acetate. ([bheaa])+monoethanolam ine+water system at temperatures from 303.15 to 353.15 K. Journal of Molecular Liquids 181, 121-126 (2013).

19) Doerr N., Gebeshuber C., Holzer D., Wanzenboeck H.D., Ecker A., Pauscitz A., Franek F., Evaluation of ionic liquids as lubricants, Journal of Microengineering and Nanoelectronics. 1, 29-34 (2010).

(Received 20/12/2017; accepted 22/2/2018) 


\section{كزيونائص الزيولوجيه والفيزيائيه للسوائل الايونيه المقترنه بكاتيونات الامونيوم المستخدمه

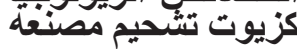

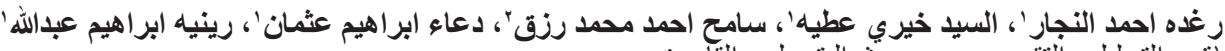

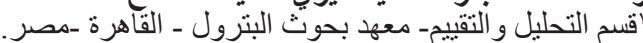

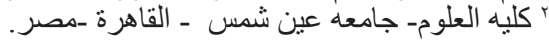

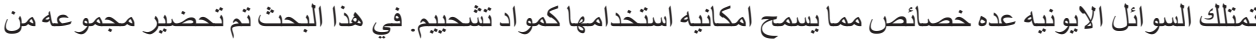

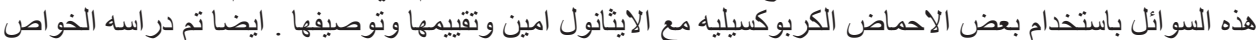

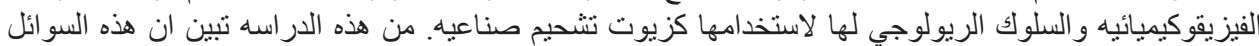

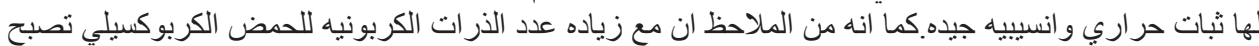

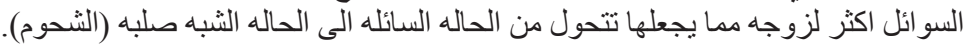

